\title{
Animal Models in Covid-19 Research: A Scientometric Assessment of Indian Publications during 2020-21
}

\author{
BM Gupta ${ }^{1,},{ }^{,}$M Surulinathi ${ }^{2}$, KK Mueen Ahmed $^{3}$ \\ Formerly with CSIR-NISTADS of Science, Technology and Development Studies, New Delhi, INDIA \\ 2Bharathidasan University, Department of LIS, Tiruchirappalli, Tamil Nadu, INDIA. \\ ${ }^{3}$ Phcog.Net \#17, Cox Town, Bengaluru, Karnataka, INDIA.
}

\section{ABSTRACT}

Background: Animal studies are an indispensable part of fundamental and applied research essential for the advancement of human and veterinary health, including the current global quest for treatments and a vaccine development to combat the infectious diseases. This necessity is now clearly highlighted by the ongoing Covid-19 pandemic More recently a growing number of studies are published on this theme. Therefore, a bibliometric analysis of research on "Animal models in Covid-19" research is necessary and it is likely to focus on current status of research and indicate future direction in this study. Materials and Methods: The India's originated literature is searched on "Animal Models in Covid-19" using two set of keywords related to Covid-19 and animals in "Keyword" and "Title" (Title of articles) tags to reach the relevant publications. VOSviewer was applied to perform the bibliometric analysis of these articles. Bibliographical data obtained from above search strategy was analysed by using well-established bibliometric indices. Results: The bibliometric analysis of India's literature on the topic "Animal Models in Covid-19" research indicates that there were 2343 India's publications indexed in Scopus database during 2020-21. The topic witnessed the uneven participation of more than 160 countries, where $88.63 \%$ and more than $100.0 \%$ share of the global publications and citations share caming from top 10 countries. USA leads the ranking with global publication share of $28.16 \%$ share, followed by China (13.30\%, U.K. (10.67\%), Italy (9.93\%). India's research output on this topic registered $7.46 \%$ share to global output. The 496 organizations and 869 authors participated in India's research on "Animal Model in Covid-19", of which the top 25 Indian organizations and 25 authors contributed $46.58 \%$ and $22.60 \%$ share to India's national
\end{abstract}

publication output and $61.19 \%$ and $48.8 \%$ share to India's citation output respectively. AIIMS - New Delhi, PGIMER-Chandigarh, and IVRI-Bareilly were the most productive organizations (with 118,115 and 68 publications). IVRIBareilly, PGIMER-Chandigarh and College of Veterinary Science, Mathura were the impactful organizations in terms of citation per paper and relative citation index. K. Dharma, R. Tiwari and Y.S. Malik were the most productive authors (with 63,35 and 27 papers). H. Harapan, A.K.Singh and A Misra were the most impactful authors (with 90.42, 88.20 and 73.31 CPP).. International Journal of Research in Pharmaceutical Sciences, Indian Journal of Medical Research and Diabetes and Metabolic Syndromes. Clinical Research and Review were the most productive journals (with 72, 56 and 50 papers). Conclusion: The paper provides a understanding of the current research on animal models presently used in Covid-19 research in India, identify key players and their collaboration patterns and key sub-fields, which may be useful to practicing scholars and clinicians to advance their future research in a more effective manner and to policymakers in deciding the area of research to be funded in future.

Key words: Covid-19, Animal Models, Global publications, Indian Publications, Bibliometrics, Scientometrics1.

\section{Correspondence}

Dr. BM Gupta,

Formerly with CSIR-NISTADS, New Delhi, INDIA.

Email id: bmgupta1@gmail.com

DOI: 10.5530/jyp.2021.13s.71

\section{INTRODUCTION}

The remarkable anatomical and physiological similarities between humans and animals, particularly mammals, have prompted researchers to investigate a large range of mechanisms and assess novel therapies in animal models before applying their discoveries to humans. ${ }^{1}$ Animal models have the same receptors as those present in humans, which help viruses during the attachment and entry process, and the outcome of infection should match the severity observed in humans. But in many emerging diseases, in vitro studies cannot completely simulate human pathophysiology. Besides, the immunological components are very complex in humans, which cannot be proven in the in vitro experiments. However, despite differences between animal models and humans, critical information related to the pathogenesis, prevention and treatment of newly emerging infectious diseases can still be discovered. ${ }^{2}$ In February 2020, the World Health Organization (WHO) assembled an international panel to develop animal models for Covid-19 to accelerate the testing of vaccines and therapeutic agents. ${ }^{3}$ Recent detection of coronavirus virus in pet, zoo, wild, and farm animals have compelled inquiry regarding the zoonotic (animal-to-human) and reverse zoonotic (human-to-animal) transmissibility of SARS-CoV-2 with the potential of Covid-19 pandemic evolving into a panzootic. ${ }^{4}$ Results obtained from experimental studies indicate that animal species such as cats, ferrets, raccoon dogs, cynomolgus macaques, rhesus macaques, white-tailed deer, rabbits, Egyptian fruit bats, and Syrian hamsters are susceptible to SARS-CoV-2 infection, and that cat-to-cat and ferret-to-ferret transmission can take place via contact and air. However, natural infections of SARS-CoV-2 have been reported only in pet dogs and cats, tigers, lions, snow leopards, pumas, and gorillas at zoos, and farmed mink and ferrets. Even though human-to-animal spillover has been reported at several instances, SARS-CoV-2 transmission from animals-to-humans has only been reported from mink-to-humans in mink farms. ${ }^{5}$ Continued refinement and development of animal models for Covid-19 will contribute to the development of vaccines, therapeutic agents and other countermeasures. Large-scale clinical trials are currently underway to test multiple candidate preventative and therapeutic interventions in humans. The outcomes of these clinical-efficacy trials will allow an unprecedented opportunity for the back-validation and refinement of these animal models. ${ }^{3}$

This is an open access article distributed under the terms of the Creative Commons Attribution-NonCommercial-ShareAlike 4.0 License, which allows others to remix, tweak, and build upon the work non-commercially, as long as the author is credited and the new creations are licensed under the identical terms. 


\section{Literature Review}

Although quite a large number of bibliometric studies have been conducted on Covid-19, but no studies have been undertaken on animal models in Covid-19. Among bibliometric studies in particular on Covid-19, Gupta, Dhawan, Ahmed and Mamdapur ${ }^{6}$ evaluated global research (103054 records) on Covid-19 on select bibliometric indicators. It presents a bibliometric profile of most influential countries, organizations, authors and journals, and also describes their collaborative linkages. It identifies broad subject areas of research, most significant keywords and highly-cited papers related to Covid-19. Among studies related to animal models in general, Wang, Chen, $\mathrm{Xu}$ and $\mathrm{Cui}^{7}$ used a bibliometric method to analyze the studies (8636 articles) of rat and mouse Parkinson's Disease (PD) models based on research published between 2009 and 2018 in the Web of Science (WOS) database using CiteSpace V software. According to the bibliometric analysis, studies on PD were focused on the mechanisms of oxidative stress, neuro inflammation, and autophagy. Since there were no bibliometric studies available on this topic, the authors therefore decided to undertake a study on bibliometric assessment of India's research on use of animal models in Covid-19 research. The main objective was to identify the current status and trends of research, to identify major subject areas and important keywords, to identify important players (organizations and authors), to identify important sources used and to analyse the characterstics of high cited papers. The study mainly used publication, citations and international collaborative papers to understand the research activity on this topic.

\section{METHODOLOGY}

Research publications on the theme "Animal Models in Covid-19" were identified, retrieved and downloaded from the Scopus database (https:// www.scopus.com), using two sets of keywords related to topic under study. The keywords were incorporated in field tags, "Keyword" or "Title" (Article Title) and limited the search to 2020-21 publication years. The search yielded a total 2343 records published by India. The publications data after downloading was analyzed using additional analytical provisions as available in the Scopus database.

Publication characteristics were tabulated, including titles, authors, co-cited authors, journal sources, keywords, affiliations of authors, countries or regions to which the authors belong. Co-cited authors means that the authors have been cited together. Biblioshiny software was utilized to analyze the relationships among the most productive countries, research institutions, and among frequently used keywords. The study performed cluster analysis and generated social network maps (consist of nodes and links) for countries, institutions and keywords by Biblioshiny. Cluster was also obtained by Biblioshiny via analyzing the frequency of the same keywords appearing within the different papers.

TITLE ("COVID 19" OR "2019 novel coronavirus" OR "coronavirus 2019” OR “coronavirus disease 2019” OR “2019-novel CoV” OR “2019 ncov" OR covid 2019 OR covid19 OR “corona virus 2019” OR ncov-2019 OR ncov2019 OR "nCoV 2019" OR 2019-ncov OR covid-19 OR "Severe acute respiratory syndrome coronavirus 2" OR "SARS-CoV-2") OR KEY ( "COVID 19" OR "2019 novel coronavirus" OR "coronavirus 2019” OR “coronavirus disease 2019” OR "2019-novel CoV” OR “2019 ncov" OR covid 2019 OR covid19 OR "corona virus 2019” OR ncov-2019 OR ncov2019 OR "nCoV 2019” OR 2019-ncov OR covid-19 OR "Severe acute respiratory syndrome coronavirus 2" OR "SARS-CoV-2" ) AND KEY ( nonhuman ${ }^{\star}$ OR animal ${ }^{\star}$ OR ferret ${ }^{\star}$ OR hamster ${ }^{\star}$ OR mice* OR monkey ${ }^{\star}$ OR redent ${ }^{\star}$ OR rat $^{\star}$ OR rabbit ${ }^{\star}$ OR cats OR dog OR macaqies ${ }^{\star}$ OR pig OR tiger OR bat ) AND ( LIMIT-TO ( AFFILCOUNTRY,'India”).

\section{RESULTS}

\section{Overall Output}

As seen from the Scopus database, the global research on the topic of "Animal Models in Covid-19" studies accumulated a total 31402 during 2000-21. India's contribution to Animal Model in Covid-19 research during the period was 2343 publications, a $7.46 \%$ global share $(2020=1360 ; 2021=983)$. The distribution of global research output by participating countries (160) is highly skewed. For example, 53 countries contributed 1-10 papers each, 19 countries 11-20 papers each, 22 countries 21-50 papers each, 13 countries 51-100 papers each, 36 countries 101-500 papers each, 6 countries 501-100 papers each, 6 countries 1001-2000 papers each and 5 countries 2343-8843 papers each.

The top 10 countries together accounted for a $90.23 \%$ share. The USA tops the list of most productive countries with a $28.16 \%$ share, followed by China, U.K. and Italy $(13.3 \%, 10.67 \%$ and $9.93 \%$ respectively). India ranks at the fifth position in the tally with a $7.46 \%$ share (Table 1 ). The global share of Germany, France, Canada, Spain and Iran ranges from $3.49 \%$ to $4.73 \%$.

India's on research on "Animal Models in Covid-19" (2343 publications) received 24595 citations since publication and scored an average of 10.50 citations per paper. The citation count was taken on 18.8.2021.

A $20.91 \%$ share (490) of India's 2343 publications received extra-mural funding support from 100+ agencies and accrued 6608 citations during the period. The citation performance of funded papers was an average of 13.48 citations per paper. The leading global funding agencies were Department of Science and Technology, India (98 papers), Indian Council of Medical Research (66 papers), Department of Biotechnology, India (64 papers), Science and Engineering Board, India (58 papers), Council of Scientific and Industrial Research, India (57 papers), National Institute of Health, USA (40 papers), University Grants Commission, India (28 papers), etc.

Of the total India's publications on this theme, articles constituted the largest group (a $47.41 \%$ share), followed by reviews and letters $(28.68 \%$ and $14.0 \%)$, notes, editorials and conference papers $(3.67 \%, 3.07 \%$ and $2.05 \%)$, short surveys,book chapters and retracted $(0.60 \%, 0.47 \%$ and $0.04 \%)$.

A $32.37 \%$ share (756) of India's publications on "Animal Models in Covid-19" research, were involved in international collaboration with $50+$ countries. These 756 International collaborative papers received

Table 1: Global Contribution of Top 10 Countries in "Animal Models in Covid-19" Research during 2021-21.

\begin{tabular}{clcc}
\hline S.No & Name of the country & TP & \%TP \\
\hline 1 & USA & 8843 & 28.16 \\
2 & China & 4178 & 13.30 \\
3 & U.K.. & 3350 & 10.67 \\
4 & Italy & 3117 & 9.93 \\
5 & India & 2343 & 7.46 \\
6 & Germany & 1486 & 4.73 \\
7 & France & 1399 & 4.46 \\
8 & Canada & 1282 & 4.08 \\
9 & Spain & 1242 & 3.96 \\
10 & Iran & 1095 & 3.49 \\
& Total & 28335 & 90.23 \\
& Global total & 31402 & \\
\hline
\end{tabular}


11699 citations, an average of 15.47 citations per paper. India's collaboration with the USA the most, a $41.67 \%$ of collaborative papers (756), followed by U.K. (20.9\%), Saudi Arabia (10.49\%), Australia (10.45\%), China (9.65\%), Italy (8.46\%), South Korea (7.93\%), Germany $(7.14 \%)$ and Japan $(7.01 \%)$. Figure 1 provides a visual chart of international collaborating countries network of India with other top countries in the subject.

\section{Subject-Wise Distribution of Publications}

The 2343 publications on "Animal Models in Covid-19" were classified by Scopus classification (Table 2). Medicine accounts for the most publications in the research studies (a 92.82\% share), followed by Biochemistry, Genetics and Molecular Biology (25.88\%), Immunology and Microbiology (7.85\%), Pharmacology, Toxicology and Pharmaceutics (3.34\%) and Neurosciences (3.01\%). In terms of citation performance, publications on Biochemistry, Genetics and Molecular Biology registered the highest citations per paper (11.13) and the least by Immunology and Microbiology (5.72 CPP).

\section{Significant Keywords}

Keywords allude to some broad ideas about the ongoing research trends on the theme of the topic under study. 75 significant keywords were identified from the literature on "Animal Models in Covid-19". The frequency of their occurrence in the literature varied from 81 to 2221 times. The keyword 'Covid-19' occurred the most number of time (2221), followed by keyword "Non-Human (1341), Pandemic (1141), 'Virus Pneumonia" (578), "Betacoronovirus(520), "Virology" (420), etc. Among animal models, the maximum emphasis was on non-humans (1341), followed by animals (289), rats (66), bat (47), mouse (39), Choroptera (27), dogs (18), cats (16), camel (14), monkeys (13), pigs

Table 2: Subject-Wise Distribution of Publications on “Animal Models in Covid-19" 2020-21.

\begin{tabular}{|c|c|c|c|c|c|}
\hline S.No & Name of the Subject & TP & TC & CPP & \%TP \\
\hline 1 & Medicine & 556 & 5404 & 9.72 & 92.82 \\
\hline 2 & $\begin{array}{l}\text { Biochemistry, Genetics and } \\
\text { Molecular Biology }\end{array}$ & 155 & 1725 & 11.13 & 25.88 \\
\hline 3 & Immunology and Microbiology & 47 & 269 & 5.72 & 7.85 \\
\hline 4 & $\begin{array}{l}\text { Pharmacology, Toxicology and } \\
\text { Pharmaceutics }\end{array}$ & 20 & 143 & 7.15 & 3.34 \\
\hline \multirow[t]{2}{*}{5} & Neurosciences & 18 & 114 & 6.33 & 3.01 \\
\hline & Global Total & 599 & 5878 & 9.81 & 100.00 \\
\hline
\end{tabular}

$\mathrm{TP}=$ Total papers; $\mathrm{TC}=$ Total citations; $\mathrm{CPP}=$ Citations per paper

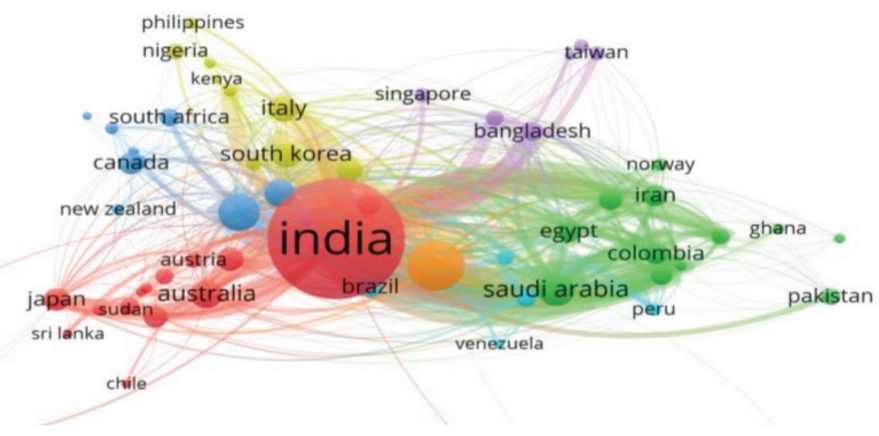

Figure 1: Network Chart of Countries in International collaboration with India in 'Animal Models in Covid-19 Research.
(12), etc. (Table 3). Figure 2 presents a conceptual structure map of significant keywords and also carried out to Correspondence analyses (MCA) of Significant Keywords

\section{Type of Studies}

Animal Models in Covid-19' research studies can be classified under various types. It was observed that studies related to "Treatment" type accounts for the most number of publications (a $28.08 \%$ share), followed by "Clinical Studies" type (21.47\%), "Epdemiology" (16.46\%), "Pathophysiology" (14.90\%), "Genetics" (10.20\%), "Risk Factors"(8.11\%) and "Complications" (6.40\%). In terms of performance on citations, "Complications" type registered the most citations per paper (19.95) and "Epidemiology" type for the least number (11.65 CPP) (Table 4)

\section{Profile of Top 25 Organizations}

In all 496 organizations from India contributed to "Animal Models in Covid-19" research but their research productivity varied widely. For instance, 277 organizations contributed 1-5 papers each, 112 organizations 6-10 papers each, 71 organizations 11-20 papers each, 30 organizations 21-50 papers each, 4 organizations 51-69 papers each and just 2 organizations 115-188 papers each.

The top 25 organization contributed 24 to 118 papers each and together they contributed a $42.08 \%$ share (986 out of 2343 papers) and received a $53.84 \%$ share in global citations (13243). On further analysis, it was observed that: (i) Eight of 25 organizations individually contributed more number of papers than their group average (16.76) and (ii) Six organizations individually registered their performance in terms of citations per paper and relative citation index above their group average (32.11 CPP and 3.06 (global av being 1) respectively). Table 5 lists the performance of 7 most productive and 7 most impactful organizations. Figure 3 provides a visual view of institutional collaborative networks in 'Animal Models in Covid-9' research in India during 2020-21.

\section{Profile of Top 25 Authors}

In all 869 authors from 469 organizations from India contributed to "Animal Models in Covid-19" research but their productivity is spread out widely. For instance, 769 authors contributed 1-5 papers each, 75 authors 6-10 papers each, 18 authors 11-20 papers each and 7 authors 21-63 papers each.

The top 25 authors individually contributed 9 to 63 papers each and together they contributed a $16.03 \%$ share (96) and a $8.97 \%$ share (527) in global citations. On further analysis, it was observed that: (i) Seventeen of 25 top authors contributed more number of papers than their group average (3.84) and (ii) Nine authors registered their performance in citations per paper and relative citation index above their group average (5.49 CPP and 0.61 (global av being 1)). Table 6 lists the top 7 most productive authors and 7 most impactful authors. Figure 4 provides a networks of top 25 collaborating authors

\section{Profile of Top 25 Journals}

Of the total 2343 publications by India on "Animal Models in Covid-19", a $97.61 \%$ share (2287 publications) appeared as articles in 367 journals, $1.84 \%$ (43) in conference proceedings and $0.55 \%$ (13) in book series. The contribution by research authors to 367 journals is widely spread out. For instance, 280 journals contributed 1-5 paper each, 44 journals 6-10 papers each, 32 journals 11-20 papers each, 9 journals 21-50 papers each and 2 journals 56-72 papers each. The contribution to top 25 journals individually varied 14 to 72 papers and together they accounted for a $27.20 \%$ share of total output by India in this research field.

On further analysis it was found that (I) the top seven productive journals include International Journal of Research in Pharmaceutical 
Table 3: List of Significant Keywords appearing in Literature on "Animal Models in Covid-19".

\begin{tabular}{|c|c|c|c|c|c|c|c|c|}
\hline S.No. & Keywords & TP & S.No & Keywords & TP & S.No & Keywords & TP \\
\hline 1 & Covid-19 & 2221 & 26 & Quarantine & 151 & 51 & Dexamethasone & 81 \\
\hline 2 & Non-Human & 1341 & 27 & Vaccination & 150 & 52 & Cardiovascular Disease & 82 \\
\hline 3 & Pandemic & 1141 & 28 & Interleuken 6 & 141 & 53 & Case Reports & 82 \\
\hline 4 & Virus Pneumonia & 578 & 29 & Hypertension & 137 & 54 & Diarrhea & 82 \\
\hline 5 & Betacoronovirus & 520 & 30 & Tocilizumab & 136 & 55 & Drug Design & 83 \\
\hline 6 & Virology & 420 & 31 & Favipiravir & 133 & 56 & Lockdown & 82 \\
\hline 7 & Angiotensin Converting Enzyme 2 & 344 & 32 & Virus RNA & 127 & 57 & Hand Washing & 81 \\
\hline 8 & Hydroxycholoroquine & 297 & 33 & Inflammation & 126 & 58 & Rats & 66 \\
\hline 9 & Animals & 289 & 34 & Azithromycin & 122 & 59 & Bat & 47 \\
\hline 10 & Remdesivir & 268 & 35 & Pathogenesis & 120 & 60 & Mouse & 39 \\
\hline 11 & Immunology & 243 & 36 & C.Reactive Protein & 118 & 61 & Choroptera & 27 \\
\hline 12 & Antiviral Agents & 250 & 37 & Molecular Dynamics & 108 & 62 & Dogs & 18 \\
\hline 13 & Drug Effect & 234 & 38 & Tumor Necroosis Factor & 108 & 63 & Cats & 16 \\
\hline 14 & Immune Response & 213 & 39 & Drug Safety & 107 & 64 & Camel & 14 \\
\hline 15 & CHoloroquine & 208 & 40 & Ribavirin & 107 & 65 & Monkeys & 13 \\
\hline 16 & Comorbidity & 195 & 41 & Computer Model & 106 & 66 & Pigs & 12 \\
\hline 17 & Adult Respiratory Distress Syndrome & 184 & 42 & $\begin{array}{l}\text { Computer-Assisted } \\
\text { Tomography }\end{array}$ & 102 & 67 & Hamster & 10 \\
\hline 18 & Molecular Docking & 184 & 43 & THroax Radiography & 102 & 68 & Bovine & 9 \\
\hline 19 & Coronovirus Spikr Glyoprotein & 177 & 44 & Immunomodulation & 100 & 69 & Tiger & 7 \\
\hline 20 & Dyspnea & 168 & 45 & Intensive Care Unit & 98 & 70 & Swine & 5 \\
\hline 21 & Diabetes Mellitus & 167 & 46 & Lopinavir & 97 & 71 & Cattele & 5 \\
\hline 22 & Virus Genome & 159 & 47 & Ritonavir & 97 & 72 & Rodents & 5 \\
\hline 23 & Drug Repositioning & 158 & 48 & Social Distancing & 89 & 73 & Horse & 4 \\
\hline 24 & Cytokine Storm & 158 & 49 & Corticosteroid & 87 & 74 & Horse & 4 \\
\hline 25 & Lopinavir Plus Ritonavir & 152 & 50 & $\begin{array}{l}\text { Molecular Docking } \\
\text { Simulation }\end{array}$ & 86 & 75 & Ferrets & 3 \\
\hline
\end{tabular}

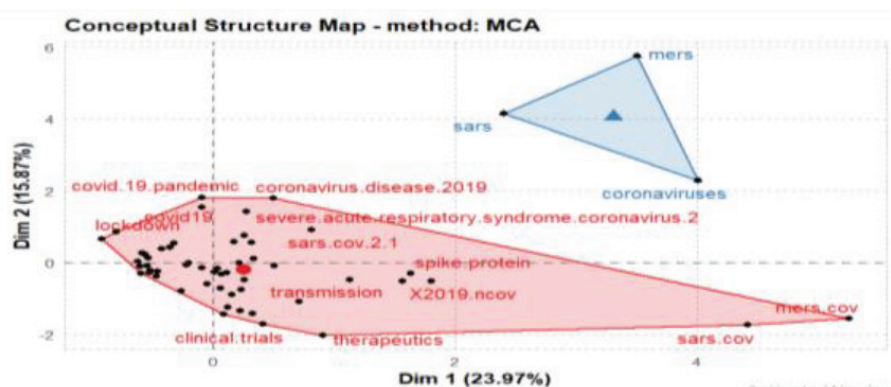

Figure 2: Conceptual Structure: Map-method Correspondence analysis (MCA) of Significant Keywords.

Sciences (72 papers), Indian Journal of Medical Research (56 papers), Diabetes and Metabolic Syndromes. Clinical Research and Review (50 papers), Medical Hypothesis (38 papers), Journal of Medical Virology (29 papers), Journal of Pure and Applied Microbiology (28 papers) and Indian Journal of Critical Care Medicine (25 papers) and; and (ii) the performance of top seven reporting journals in terms of citations per paper was as follows: Indian Journal of Pediatrics (78.67 CPP), Journal
Table 4: Distribution of Publications by Types of Study.

\begin{tabular}{clcccc}
\hline S.No. & Type of Study* & TP & TC & CPP & \%TP \\
\hline 1 & Clinical Studies & 503 & 8154 & 16.21 & 21.47 \\
2 & Pathophysiology & 349 & 5107 & 14.63 & 14.90 \\
3 & Epidemiology & 395 & 4601 & 11.65 & 16.86 \\
4 & Genetics & 239 & 2957 & 12.37 & 10.20 \\
5 & Risk Factor & 190 & 2873 & 15.12 & 8.11 \\
6 & Complications & 150 & 2993 & 19.95 & 6.40 \\
7 & Treatment & 658 & 8937 & 13.58 & 28.08 \\
& Total & 2343 & & & \\
\hline
\end{tabular}

There is overlapping of studies under various types of studies

of Biomolecuar Structure and Dynamics (51.3 CPP), Science of the Total Environment (37.71 CPP), Diabetes and Metabolic Syndromes. Clinical Research and Review (28.34 CPP), Journal of Medical VIrology (21.97 CPP), Asian Journal of Psychiatry (21.59) and Human Vaccine and Immunotherapeutics (20.94 CPP). Figure 5 provides a three fields plot of the journals analysis: (Left field: Journals; Middle field: Titles; Right field: Authors) 
Table 5: Profile of Top 7 Most Productive and Most Impactful Organizations from India on Animal Models in Covid-19 Research- $2020-21$.

\begin{tabular}{|c|c|c|c|c|c|c|c|c|}
\hline S.No & Name of the Organization & TP & TC & CPP & HI & ICP & $\%$ ICP & $\mathrm{RCl}$ \\
\hline \multicolumn{9}{|c|}{ Top 7 Most Productive Organizations } \\
\hline 1 & All India Institute of Medical Sciences (AIIMS), New Delhi & 118 & 1000 & 8.47 & 14 & 12 & 10.17 & 0.81 \\
\hline 2 & $\begin{array}{l}\text { Postgraduate Institute of Medical Education and Research } \\
\text { (PGIMER), Chandigarh }\end{array}$ & 115 & 1441 & 12.53 & 17 & 15 & 13.04 & 1.19 \\
\hline 3 & Indian Veterinary Research Institute (IVRI), Bareilly & 68 & 2697 & 39.66 & 19 & 48 & 70.59 & 3.78 \\
\hline 4 & Datta Megha Institute of Medical Sciences & 53 & 57 & 1.08 & 4 & 1 & 1.89 & 0.10 \\
\hline 5 & Amity University, Noida & 39 & 220 & 5.64 & 8 & 13 & 33.33 & 0.54 \\
\hline 6 & Manipal Acdemy of Higher Education (MAHE) & 38 & 297 & 7.82 & 8 & 12 & 31.58 & 0.74 \\
\hline 7 & $\begin{array}{l}\text { Sanjay Gandhi Postgraduate Institute of Medical Sciences } \\
\text { (SGPGIMS), Lucknow }\end{array}$ & 37 & 417 & 11.27 & 9 & 11 & 29.73 & 1.07 \\
\hline \multicolumn{9}{|c|}{ Top 7 Most Impactful Organizations } \\
\hline 1 & $\begin{array}{l}\text { U.P. Pandit Deen Dayal Upadhayaya Pashu Chiksa Vigyan } \\
\text { Vishwaavidalaya Evam Go Anusandhan }\end{array}$ & 29 & 1300 & 44.83 & 15 & 24 & 82.76 & 4.27 \\
\hline 2 & College of Veterinary Science, Mathura & 36 & 1437 & 39.92 & 16 & 28 & 77.78 & 3.80 \\
\hline 3 & Indian Veterinary Research Institute (IVRI), Bareilly & 68 & 2697 & 39.66 & 19 & 48 & 70.59 & 3.78 \\
\hline 4 & Jamia Millia Islamia, New Delhi & 27 & 625 & 23.15 & 10 & 9 & 33.33 & 2.20 \\
\hline 5 & Christian Medical College (CMC), Vellore & 35 & 732 & 20.91 & 9 & 7 & 20.00 & 1.99 \\
\hline 6 & Indian Institute of Technology (IIT), New Delhi & 29 & 437 & 15.07 & 9 & 6 & 20.69 & 1.44 \\
\hline 7 & $\begin{array}{l}\text { Postgraduate Institute of Medical Education and Research } \\
\text { (PGUIMER), Chandigarh }\end{array}$ & 115 & 1441 & 12.53 & 17 & 15 & 13.04 & 1.19 \\
\hline
\end{tabular}

$\mathrm{TP}=$ Total papers; $\mathrm{TC}=$ Total citations; $\mathrm{CPP}=$ Citations per paper; $\mathrm{ICP}=$ International collaborative papers; $\mathrm{HI}=h$-Index; $\mathrm{RCI}=\mathrm{Relative}$ citation index

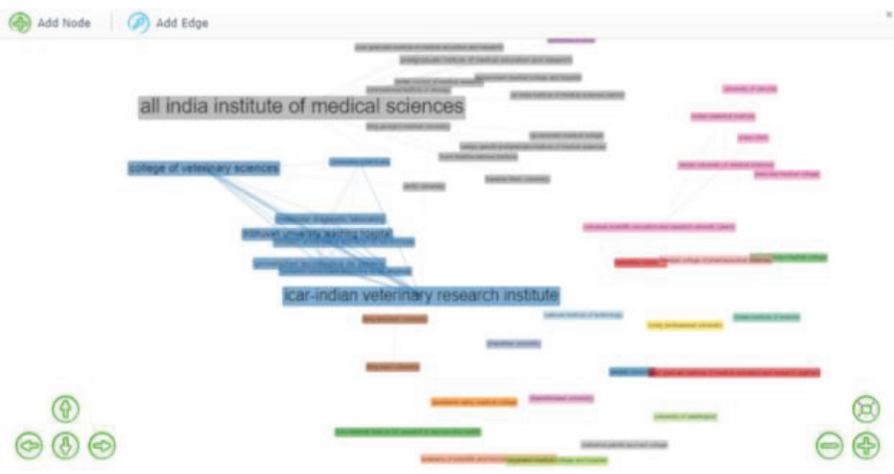

Figure 3: 'Animal Models of Covid-19' research in India - Network Chart of Collaborating Organizations.

\section{High-Cited Papers}

A $1.54 \%$ share (36 publications) of 2343 publications by India on "Animal Models in Covid-19 research, (assumed as high-cited here) received 103-1010 citations per paper since their publication. Together these highly cited papers received 8910 citations, an average of 247.5 citations per paper. Of the 36 highly cited papers, 21 received 103-192 citations, 8 received 204-253 citations, 5 received 327-503 citations and 2 papers received $932-1010$ citations.

Among 36 high-cited papers, the USA accounts for the most publications in collaboration with India (8 papers), followed by China, Columbia, Saudi Arabia, Thailand and U.K. (4 papers each), Australia, South Korea and Spain (3 papers each), France, Iran, Japan, Nepal, Netherlands and Peru (2 papers each) and 20 other countries collaborated with India in 1 paper each.
These 36 high-cited papers by publication type include 19 articles, 14 reviews, 2 letters and 1 note. In all 232 authors from 291 organizations from India contributed to 36 highly cited papers. Seven of these highly cited papers were non-collaborative papers and 29 as collaborative papers (13 national collaborative and 16 international collaborative).

The 36 high-cited papers were published in 26 journals, with 4 papers in Journal of Molecular Structure and Dynamics, 3 in Diabetic and Metabolic Syndromes. Clinical Research and Review, 2 each in The BMJ, Asian Journal of Psychiatry, Clinical Microbiological Review, Journal of Medical Virology and Science of the Total Environment and 1 paper each in 19 other journals. Figure 6 provides a word cloud title analysis.

\section{RESULTS}

About 160 countries contributed to "Animal Models in Covid-19" research and generated a total of 31402 global publications during 2020-21. Despite witnessing a global level participation, research in the subject was dominated mainly by top 10 countries, with a $90.23 \%$ global share. The USA contributed the most number of publications with a $28.16 \%$ global share, followed by China, U.K. and Italy $(13.3 \%, 10.67 \%$ and $9.93 \%)$, etc. India ranks at the fifth position in the tally with a meagre $7.46 \%$ share (2343 publications).

India contributed a $7.46 \%$ global share (2343 publications), received a total of 24595 citations, an average of 10.5 citations per publication. Only a $1.54 \%$ share (36) India's publications received high citations 103 to 1010 citations. Together these 36 highly cited papers registered 8910 citations, an average of 247.5 citations per paper. A $20.91 \%$ share (490) of the total output by India received extramural funding support and it accounted for 6608 citations, averaging 13.48 citations per publication. Most publications by India, a $92.82 \%$ share, appeared in "Medicine" journals. Most publications organized by type of studies belonged to 'treatment' category $(28.08 \%)$, followed by 'clinical studies' type studies $(25.88 \%)$. 
Gupta, et al.: A Scientometric Assessment of India’s Research on Animal Models in Covid-19

Table 6: Profile of Top 7 Most Productive and Most Impactful Authors on “Animal Models in Covid-19” Research in India - $2020-21$.

\begin{tabular}{|c|c|c|c|c|c|c|c|c|c|}
\hline S.No & Name of the Author & Affiliation of the Author & TP & TC & CPP & $\mathrm{HI}$ & ICP & $\% I C P$ & $\mathrm{RCl}$ \\
\hline \multicolumn{10}{|c|}{ Top 7 Most Productive Authors } \\
\hline 1 & K. Dhama & IVRI - Bareiilly & 63 & 2606 & 41.37 & 18 & 47 & 74.60 & 3.94 \\
\hline 2 & R. Tiwari & IVERI - Bareilly & 35 & 1438 & 41.09 & 16 & 28 & 80.00 & 3.91 \\
\hline 3 & Y.S.Malik & IVRI - Bareilly & 27 & 1292 & 47.85 & 13 & 21 & 77.78 & 4.56 \\
\hline 4 & K.Sharun & IVRI - Bareilly & 21 & 790 & 37.62 & 12 & 13 & 61.90 & 3.58 \\
\hline 5 & V.Wiwanitkit & Dr S.Y.Patil Vidyapeeth, Pune & 21 & 56 & 2.67 & 5 & 18 & 85.71 & 0.25 \\
\hline 6 & B.Medhi & PGIMER-Chandigarh & 20 & 406 & 20.30 & 8 & 0 & 0.00 & 1.93 \\
\hline 7 & P.Sarma & PGIMER-Chandigarh & 18 & 406 & 22.56 & 8 & 0 & 0.00 & 2.15 \\
\hline \multicolumn{10}{|c|}{ Top 7 Most Impactful Authors } \\
\hline 1 & H.Harapan & IVRI - Bareilly & 12 & 1085 & 90.42 & 7 & 12 & 100.00 & 8.61 \\
\hline 2 & A.K.Singh & $\begin{array}{l}\text { G.D.Hospital and Diabetes } \\
\text { Institute, Kolkata }\end{array}$ & 10 & 882 & 88.20 & 9 & 2 & 20.00 & 8.40 \\
\hline 3 & A.Misra & $\begin{array}{l}\text { Diabetes Foundation India, } \\
\text { New Delhi }\end{array}$ & 13 & 953 & 73.31 & 3 & 4 & 30.77 & 6.98 \\
\hline 4 & Y.S.Malik & IVRI - Bareilly & 27 & 1292 & 47.85 & 13 & 21 & 77.78 & 4.56 \\
\hline 5 & M.I.Yatoo & $\begin{array}{l}\text { Sher-e-Kashmir University of } \\
\text { Agricultural S\&T of Kashmir }\end{array}$ & 10 & 443 & 44.30 & 8 & 9 & 90.00 & 4.22 \\
\hline 6 & K. Dhama & IVRI - Bareiilly & 63 & 2606 & 41.37 & 18 & 47 & 74.60 & 3.94 \\
\hline 7 & R. Tiwari & IVERI - Bareilly & 35 & 1438 & 41.09 & 16 & 28 & 80.00 & 3.91 \\
\hline
\end{tabular}

$\mathrm{TP}=$ Total papers; $\mathrm{TC}=$ Total citations; $\mathrm{CPP}=$ Citations per paper; $\mathrm{ICP}=$ International collaborative papers; $\mathrm{HI}=h$-Index; $\mathrm{RCI}=\mathrm{Relative}$ citation index

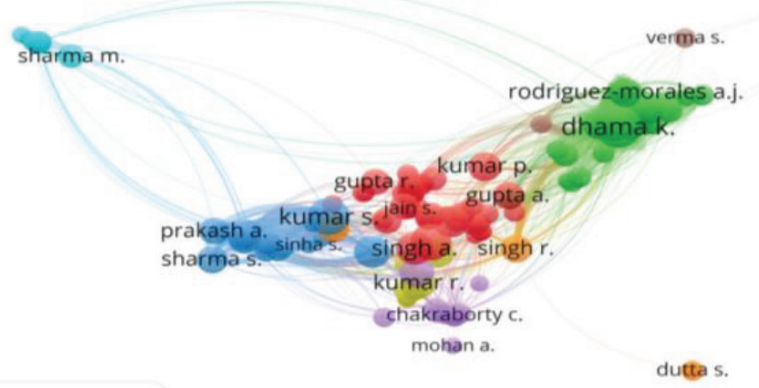

Figure 4: 'Animal Models of Covid-19' research in India - Networks of Collaborating Authors.

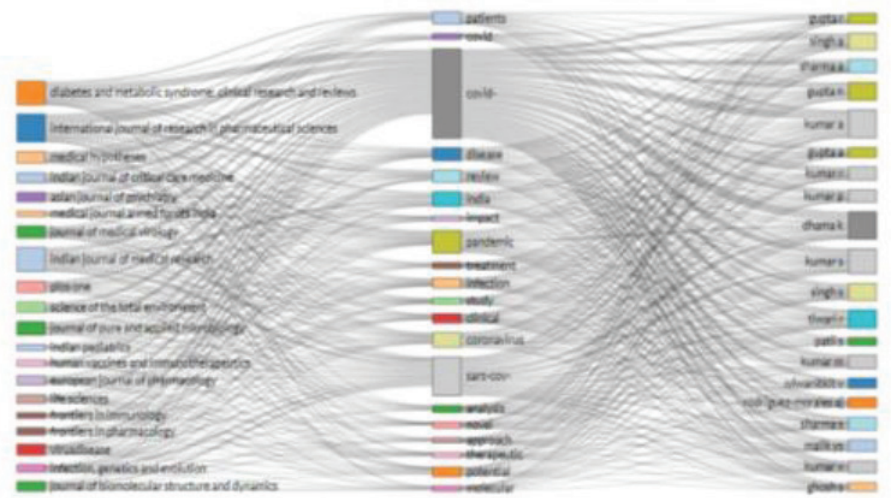

Figure 5: Three fields Plot of the Journals analysis: (Left field: Journals; Middle field: Titles; Right field: Authors).

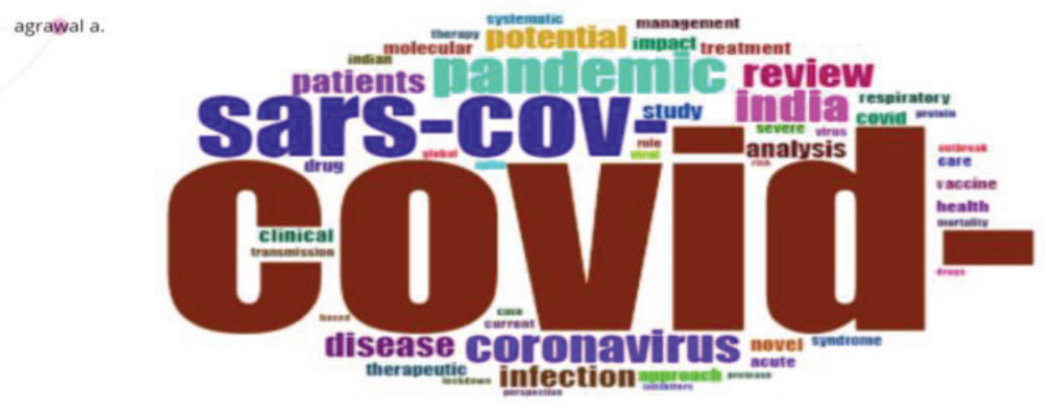

Figure 6: Word Cloud for Title Analysis.

In all, a total of 869 authors from 496 organizations contributed to research in India. The top 25 organizations and authors together contributed $42.08 \%$ and $16.03 \%$ share respectively and received $53.84 \%$ and $8.97 \%$ share in citations respectively. The top three most productive organizations are -- AIIMS- New Delhi (118 papers), PGIMER Chandigarh (115 papers), and IVRI-Bareilly (68papers). The top three most cited organizations are -- U.P.Pandit Deen Dayal Upadhayaya Pashu Chiksa Vigyan Vishwaavidalaya Evam Go Anusandhan (44.83 and 4.27), College of Veterinary Science, Mathura (39.92 and 3.8), IVRI- Bareilly (39.66 and 3.78). The most productive India's authors are K. Dhama (IVRI - Bareiilly)(63 papers), R. Tiwari (IVRI - Bareilly)(35papers), and Y.S.Malik (IVRI - Bareilly)(27 papers). The most cited authors are H.Harapan (IVRI - Bareilly)( 90.42 and 8.61), A.K.Singh (G.D.Hospital and Diabetes Institute, Kolkata)( 88.2 and 8.4), and A.Misra (Diabetes Foundation India, New Delhi) (73.31 and 6.98). The top three most productive journals in the subject are International Journal of Research in 
Pharmaceutical Sciences (72 papers), Indian Journal of Medical Research (56 papers), and Diabetes and Metabolic Syndromes. Clinical Research and Review (50 papers). The most cited journals are -- Indian Journal of Pediatrics (78.67), Journal of Biomolecuar Structure and Dynamics (51.3), and Science of the Total Environment (37.71).

\section{CONCLUSION}

Biomedical studies involving animal models have greatly contributed to the public health response to SARS-CoV-2 by assisting in the development of Covid-19 vaccines and treatments. Animal studies will continue to provide vital information as new SARS-CoV-2 variants emerge and new questions arise as to the transmissibility of these variants, whether they are more harmful to people, and if they remain sensitive to available vaccines. Animal models play a critical role in pandemic response efforts as they are necessary for evaluating the safety and effectiveness of new vaccines and therapeutics. Scientists will continue building on the lessons learned from Covid-19 to develop animal models as part of our pandemic preparedness efforts to target other emerging or re-emerging infectious diseases.

The current Covid-19 crisis highlights the reality that animal research remains essential to find solutions for human and animal health in relation to many different disorders. In the case of Covid-19, and the virus that causes it, SARS-CoV-2, the indispensability of animal research is clear. The interaction between Covid-19 and other diseases that may increase risk for death (including diabetes and heart disease) cannot be investigated in organoids. An organoid cannot model the immune system or inter-organ metabolic homeostasis mediated by, for example, hormones, neural networks and gut microbiota, ${ }^{6}$ let alone behavior and cognition. Additionally, although adaptive immunity to SARS-CoV-2 can be predicted by a variety of in vitro methods, it can only be validated in animals. This is essential for vaccine development.
Finally It is suggested that governments amd policy makers should realize that animal studies are an indispensable part of fundamental and applied research in Covid-19 and also essential for the development of new medical treatments. Rigorous research and development through extensive government and non-government funding for animal research remains necessary to secure our future health.

\section{CONFLICT OF INTEREST}

The authors declare no conflict of interest.

\section{REFERENCES}

1. Barré-Sinoussi F, Montagutelli X. Animal models are essential to biological research: issues and perspectives. Future Sci OA, FSO63. Future Sci OA: FSO63. 2015;1 (4):FSO63. doi: 10.4155/fso.15.63, PMID 28031915

2. Pandey K, Acharya A, Mohan M, Ng CL, Reid SP, Byrareddy SN. Animal models for SARS-CoV-2 research: A comprehensive literature review. Transbound Emerg Dis. 2021;68(4):1868-85. doi: 10.1111/tbed.13907, PMID 33128861.

3. Muñoz-Fontela C, Dowling WE, Funnell SGP, Gsell PS, Riveros-Balta AX, Albrecht RA, et al. Animal models for Covid-19. Nature. 2020;586(7830):509-15. doi: 10.1038/s41586-020-2787-6, PMID 32967005.

4. Goraichuk IV, Arefiev V, Stegniy BT, Gerilovych AP. Zoonotic and reverse zoonotic transmissibility of SARS-CoV-2. Virus Res. 2021;302:198473. doi: 10.1016/ j.virusres.2021.198473.

5. Sharun K, Tiwari R, Patel SK, Karthik K, lqbal Yatoo M, Malik YS, et al. Coronavirus disease 2019 (Covid-19) in domestic animals and wildlife: advances and prospects in the development of animal models for vaccine and therapeutic research. Hum Vaccin Immunother. December 1 2020;16(12):3043-54. doi: 10.1080/21645515.2020.1807802, PMID 32915100.

6. Gupta BM, Dhawan SM, Mueen Ahmed KK, Mamdapur GM. Global research on Covid-19 disease: A scientific assessment of publications during 2020-21. IJMEDPH. 2021;11(2):76-84. doi: 10.5530/ijmedph.2021.2.14.

7. Wang YQ, Chen YB, Xu D, Cui YL. Bibliometrics and visualization of the mechanisms of Parkinson's diseases based on animal models. Endocr Metab Immune Disord Drug Targets. 2020;20(10):1560-8. doi: 10.2174/18715303206662004211 03429, PMID 32316904 